\title{
Noninvasive Cardiac Imaging with Computed Tomography
}

\author{
Gregory T. Wilson, DO; Prabhakaran Gopalakrishnan, MD; and Tahir Tak, MD, Ph.D
}

\begin{abstract}
Despite major improvements in the treatment of heart disease, it remains a major source of morbidity and mortality on a global scale. Currently, invasive coronary angiography remains the gold standard for identification of obstructive coronary artery disease. However, recent advances in computerized tomographic (CT) techniques of the heart allow for accurate, non-invasive characterization of atherosclerotic coronary disease and other cardiac abnormalities. The calculation of coronary artery calcium scores with electron beam CT has largely been supplanted by high-resolution CT angiography using multi-slice detectors (MSCT) which can provide detailed multidimensional visualization of cardiac structures. Although evaluation of obstructive coronary disease is the primary use of MSCT, its use in identifying congenital defects, planning thoracic procedures and characterizing cardiac function continues to grow. Accordingly, appropriate incorporation of MSCT/CT angiography into clinical practice continues to be defined. Several limitations to MSCT remain which reduce its accuracy, such as in patients with arrhythmia and in patients with either coronary stents or heavily calcified coronaries. Despite its current limitations, MSCT remains a rapidly advancing field and an increasingly valuable tool for the non-invasive evaluation of cardiac pathology.
\end{abstract}

Keywords: Computed tomographic angiography; CT; CTA; Computed tomography, multi-detector row; Coronary artery calcification; Coronary vessels; Stenosis

O morbidity and mortality in industrialized nations. In spite of advances in medicine, cardiovascular mortality in the United States continues to be high at 332.9 deaths per 100,000 . More than half of these deaths are related to coronary artery disease (CAD). The estimated direct and indirect cost of CAD for 2006 is approximately 142.5 billion US dollars. ${ }^{1}$ Invasive coronary angiography (ICA) has been the standard of reference for diagnosis of CAD. Approximately 1.4 million diagnostic catheterizations were performed throughout the world in 2003. ${ }^{1}$ Incidence of normal angiograms has varied from $20 \%$ to $27 \%$ according to data from the Society for Cardiac Angiography and Interventions. ${ }^{2,3}$ Even though ICA is safe with an in-hospital mortality rate of $<1 \%$, it still carries a potential risk both from iodinated contrast agents used in ICA and the risks of arterial catheterization itself. Diagnostic catheterizations which are not done in conjunction with an interventional procedure, especially the ones resulting in normal angiograms, could potentially be replaced by alternate

Reprint Requests: Tahir Tak, MD, PhD, Division of Cardiovascular Diseases, Mayo Clinic, 200 First Street SW, Rochester. MN 55905, Tel: 507-284-294I,

Fax: 507-266-7929, Email: tak.tahir@mayo.edu methods of assessing CAD. Several alternate methods of assessing CAD have been studied, such as treadmill stress testing, single photon emission computed tomography (SPECT), positron emission tomography (PET), and stress echocardiography. Non-invasive diagnostic tests have their inherent limitations and do not provide morphological details of the coronary occlusion. The availability of reliable noninvasive coronary imaging could potentially decrease the need for ICA in some patients.

Noninvasive coronary imaging techniques include electron beam computed tomography (EBCT), multi-slice computed tomography (MSCT) and cardiac magnetic resonance imaging (MRI). With MSCT, the addition of multiple detector rows allowing simultaneous acquisition improves performance significantly. While single and dual detector row spiral computed tomography (CT) systems were available in the mid 1990s, 4-, 8-, 10-, 16-, 32-, 40- and 64-detector row CT scanners have since been developed, improving the spatial resolution while reducing scan time. While EBCT technology has been plagued by less

Received: January 5, 2007 Revised: April 20, 2007 Accepted: May 2, 2007

doi: $|0.3| 2 \mid / \mathrm{cmr} .2007 .747$ 
widespread availability and the technology of cardiac MRI is still evolving, MSCT angiography appears to be developing at a rapid pace.

While non-invasive coronary imaging continues to evolve, its role in current clinical practice is still being debated. Numerous studies have been done to validate the different techniques in comparison to ICA, which is still considered the gold standard. In this review, we give an overview of CT coronary angiography, the technique, applications, pitfalls and future directions.

\section{Coronary Artery Calcium}

The presence and extent of coronary artery calcification has been shown to correlate with the degree of atherosclerosis. ${ }^{4}$ Studies evaluating the clinical utility of EBCT-detected coronary artery calcification report a high negative predictive value in negative scans. This finding makes coronary artery calcification detection with $\mathrm{CT}$ a valuable test when ruling out obstructive atherosclerotic coronary disease. ${ }^{5-8}$ Due to its low specificity, calcium scoring is not suitable for the detection of significant $\mathrm{CAD}$ and should not be regarded as a sole indication for coronary angiography.

Various methods of quantifying coronary artery calcification have been proposed in order to estimate a patient's cardiovascular risk. One of the more widely used methods was originally proposed by Agatston et $\mathrm{al}^{9}$ in 1990 where a lesion's area, peak density and mean density were measured for each segmental lesion. Poor inter-scan reproducibility with Agatston scoring prompted the development of the volumetric calcium scoring algorithm by which the volume of a plaque is measured irrespective of its area or density. ${ }^{10}$ Although the volumetric score has been shown to improve reproducibility in serial scans, the Agatston scoring system is still frequently used in clinical practice.

Despite initial hopes that coronary calcium characterization offers a novel, non-invasive tool to identify patients at high risk for future major cardiovascular events (i.e., myocardial infarction, unstable angina, death), several meta-analyses report only a modest prognostic correlation between coronary calcification and significant cardiovascular outcome. ${ }^{11,12}$ One possible explanation for this observation is that vulnerable coronary plaques are often composed of noncalcified lipomatous or fibrous tissue, while heavily calcified plaques are typically less likely to rupture. ${ }^{13}$ Additionally, when compared to other well-validated diagnostic tests such as stress testing and perfusion imaging, EBCT coronary calcium scoring does not provide clearly superior diagnostic or prognostic information. ${ }^{11}$ Still, the exclusion of coronary calcifications is associated with a significantly reduced rate of future cardiovascular events. ${ }^{14}$ Overall, dedicated EBCT scanners are becoming obsolete.

However, current MSCT scanners also provide calcium scores equivalent to that of EBCT. According to the American
College of Cardiology/American Heart Association expert consensus, ${ }^{11}$ a low coronary calcium scoring makes the presence of atherosclerosis very unlikely and occurs in the majority of patients with normal coronary arteries. Therefore, CT coronary artery calcification measurements may remain a useful test to rule out significant atherosclerotic coronary disease. ${ }^{11}$ A negative predictive value of more than $95 \%$ can be achieved using the existence of any calcium as a threshold. ${ }^{15}$ The recently published cardiac CT appropriateness criteria suggest that coronary calcium scoring be reserved for patients with an intermediate or high risk of coronary disease (Framingham risk criteria), where risk stratification may aid providers in selecting treatment strategies, i.e., initiating statin therapy. ${ }^{16}$ Repeated examinations within 5 years are not recommended. ${ }^{16}$

\section{CT Angiography}

Due to the uncertain value of coronary artery calcification scores, recent emphasis has been on improving contrast enhanced CT angiography of the coronary arteries using MSCT. Addition of multiple detectors and improved temporal and spatial resolution on current $\mathrm{CT}$ scanners allow for reliable, non-invasive detection and characterization of coronary plaques. ${ }^{17-23}$ Early CT scanners using either 4 or 8 rows of detectors were able to provide accurate data on proximal coronary trunks, while newer generation scanners demonstrate reliable visualization of all coronary segments including distal branches. ${ }^{23}$

\section{Patient Preparation}

In order to obtain optimal and nearly motion-free images, the patient's heart rate should be regular and preferably $<65$ beats per minute, which is often accomplished with a pre-scan beta blocker. ${ }^{24}$ Calcium channel blockers can be given in patients with contraindications to beta blockers. The patient should avoid caffeine the day of the exam. Although no studies have evaluated its use in CT angiography, short-acting sublingual nitroglycerin ( $2 \times 0.4 \mathrm{mg}$ tablets) can be given at the time of scanning to improve visualization of the coronary lumen. ${ }^{25}$

Hypersensitivity to iodinated contrast and pregnancy remain the only true absolute contraindications for CT angiography. ${ }^{26}$ Relative contraindications for CT angiography scanning include the inability to hold one's breath for sufficient scan time, irregular or rapid $(>90)$ heart rhythm, significant renal insufficiency and inability to cooperate during scanning. Other relative contraindications are similar to those for standard CT scanning. ${ }^{25}$

\section{Data Acquisition}

Using a spiral ECG-gated image acquisition protocol, three common steps are employed. ${ }^{25}$ The first step utilizes a low energy, non-contrast topogram of the chest to define the volume and boundaries of the scan. The second step involves either a bolus timing or tracking technique to ensure appropriate coronary enhancement during scanning. The third step is the coronary CT angiography itself which covers the 


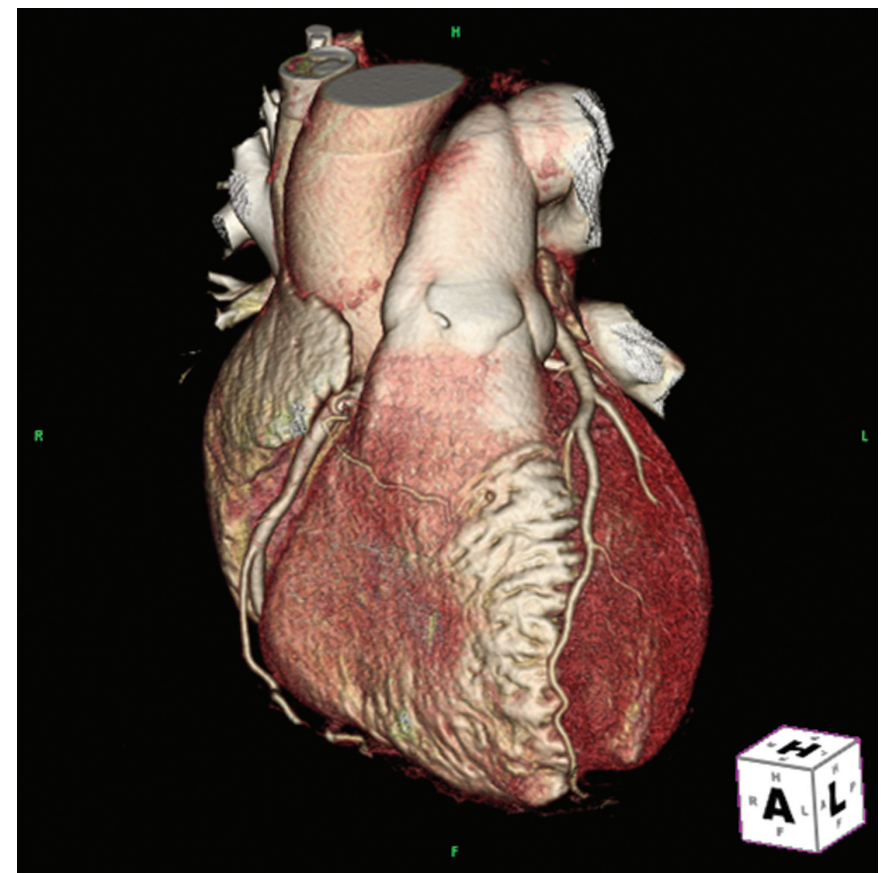

Figure 1. Three-dimensional volume rendered image of CT angiogram.

entire heart from proximal ascending aorta to the diaphragmatic surface in a single breath hold. Total volume of contrast is typically $80 \mathrm{cc}$ to $100 \mathrm{cc}$ given at a rate of $4 \mathrm{cc} / \mathrm{s}$ to $5 \mathrm{cc} / \mathrm{s}^{27-29}$ The average scan time for 64 -slice MSCT is 5 seconds to 11 seconds, depending on the vendor.

\section{Image Reconstruction and Interpretation}

Using current generation scanners, scans are obtained with continuous, spiral image acquisition. Typical reconstruction slice thickness is approximately $0.5 \mathrm{~mm}$ to $0.6 \mathrm{~mm}$ with $50 \%$ overlap between images, depending on the scanner. ${ }^{25}$ Using a technique termed retrospective image reconstruction, images can be reconstructed at any point in the cardiac cycle. ${ }^{29,30}$ Although several types of reconstruction algorithms exist, a proposed optimal reconstruction window for motion-free visualization of the coronary arteries is in mid diastole at $60 \%$ to $70 \%$ of the $\mathrm{R}-\mathrm{R}$ interval. ${ }^{30}$ Three dimensional volume rendered color images show surface anatomy (figure 1). Three dimensional maximum intensity projection and two dimensional multiplanar reformation are used to see inside the heart and visualize the coronary arteries. Furthermore, available ECG gating software allows for editing of the temporal windows to eliminate ECG irregularities, i.e., premature ventricular beats. ${ }^{29}$ The entire dataset obtained from a single multi-slice CT angiography study is extensive and can include up to 3000 axial images and 1.5 gigabytes of data, making timely assessment and data storage challenging. ${ }^{25}$

\section{Clinical Applications}

Current generation 64-slice scanners, boasting improved temporal and spatial resolution, demonstrate excellent diagnostic accuracy for both proximal coronary vessels and smaller distal vessels. ${ }^{25,28,31-38}$ MSCT allows an accurate, non-invasive evaluation of the coronary vessels in those at intermediate risk for CAD. As stated previously, MSCT scanners also provide a coronary artery calcium score.

Currently, general screening of asymptomatic populations for obstructive coronary disease, who are at low or moderate cardiac risk as determined by Framingham criteria, is not recommended. ${ }^{16}$ Concern arises regarding uncontrolled usage of such testing and the potential for unnecessary invasive work-up. ${ }^{16}$ Similarly, MSCT is currently not recommended in patients in whom other diagnostic tests already suggest high risk. 16 Current American Heart Association/American College of Cardiology recommendations suggest MSCT angiography in symptomatic patients with low to intermediate pretest probability. 39

In addition to visualizing the coronary lumen, MSCT allows characterization of the coronary atherosclerotic plaque and has shown a good correlation with intravascular ultrasound. ${ }^{31,32} \mathrm{~A}$ major goal of non-invasive imaging is to identify vulnerable plaques with the potential to rupture. ${ }^{25,32}$ The accuracy of plaque characterization seems to vary with plaque size, as larger plaques tend to be overestimated and smaller plaques may be either underestimated or not detected. ${ }^{32}$ Further technical improvements will likely enhance the ability of MSCT to characterize coronary plaques.

MSCT can also provide a measure of left ventricular function and regional wall motion, information that may prove useful when assessing patients overall cardiovascular risk. ${ }^{40,16}$ Recent comparisons have shown that left ventricular function as determined by MSCT correlates well with data obtained with echocardiography. ${ }^{40-42}$

MSCT has also been shown to be a useful tool in evaluating coronary anomalies and for planning coronary bypass grafts. ${ }^{16}$ Thoracic surgeons are able to visualize the course of vessels, as well as their relationship to adjacent structures when planning. Similarly, MSCT has been applied to coronary venous mapping for planning device implantation (i.e., left ventricular pacing leads) and for evaluating anatomic variation. Pulmonary venous mapping with CT angiography has also been useful in planning arrhythmia ablation procedures. ${ }^{43}$

MSCT remains a potential tool to determine the patency of both venous and arterial coronary bypass grafts, an asset that was considered early in the development of non-invasive imaging (figure 2). ${ }^{44,45}$ According to the recently published American College of Cardiology Foundation appropriateness criteria for cardiac CT/cardiac MRI, CT angiography of bypass grafts should be reserved for symptomatic patients. ${ }^{16}$ However, it is generally thought that MSCT cannot consistently visualize distal graft anastomosis and fails to provide a functional assessment of bypass graft flow. ${ }^{33}$ 
Recently, MSCT has been evaluated for its potential role in defining in-stent restenosis. Using 4- and 16-slice MSCT, a major limitation of MSCT has been its inability to adequately characterize stenosis within a stented segment due to significant artifact (figure 3).8,27,35 Large diameter stents $(>3 \mathrm{~mm})$ and those with thinner struts improve the accuracy for detecting and quantifying in-stent restenosis with MSCT. ${ }^{37}$ Furthermore, use of high-resolution "kernels", or specific reconstruction algorithms, can improve in-stent evaluation by fine-tuning image resolution. ${ }^{37,38}$ Still, only evaluation of stent patency is possible with an adequate diagnostic accuracy. A reliable assessment of stent stenosis cannot be expected. Therefore, conventional coronary angiography should be performed in symptomatic patients after coronary stent implantation. ${ }^{46}$

\section{Artifacts and Limitations}

Accurate image interpretation can be compromised by several types of artifacts. One of the more common problems is motion artifact induced by irregular cardiac rhythms, breathing, or other patient movement. High resolution MSCT scanners require nearly motion-free imaging to provide accurate data; consequently, MSCT is indicated only for cooperative patients with regular heart rhythms. ${ }^{25}$ Another common problem is "blooming artifact" where high-attenuation structures such as metal clips, stents, and calcified plaques may obscure adjacent tissue. ${ }^{25}$ This phenomenon can significantly limit the accuracy of MSCT in determining coronary stenosis in a heavily calcified vessel. Similarly, dense structures or calcification may cause streaking through an image, a phenomenon termed "beam hardening" artifact. ${ }^{25}$ Furthermore, if the timing of the

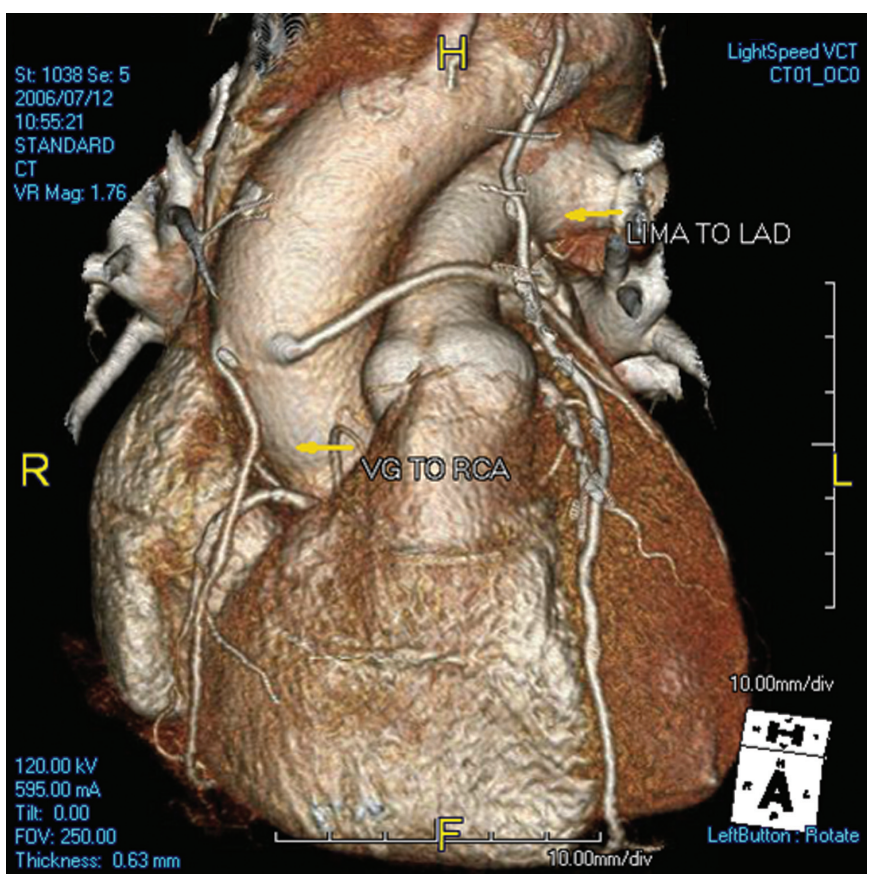

Figure 2. Three-dimensional volume rendered image of angiogram demonstrating coronary artery bypass grafts. VG, vein graft; RCA, right coronary artery; LIMA, left internal mammary artery; $L A D$, left anterior descending artery; $R$, right.

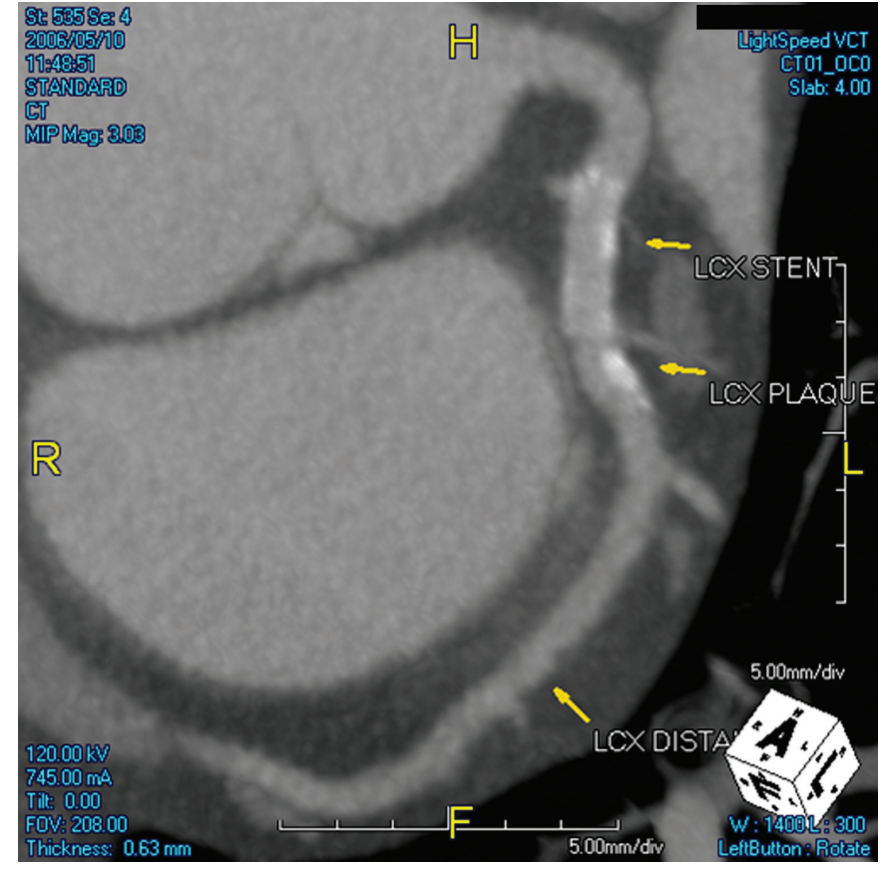

Figure 3. CT axial image demonstrating intracoronary stent in the left circumflex ( $L C X)$ artery and the presence of plaque distal to the stent (LCX plaque).

contrast bolus is not optimal, inadequate enhancement of the coronary tree results. ${ }^{29}$

With MSCT, some concern has been raised regarding the radiation dose administered to patients. ${ }^{47}$ The effective radiation dose using a 64-slice MSCT is approximately $6.5 \mathrm{mSv}$ to $15 \mathrm{mSv} .{ }^{48}$ This value is approximately two to three times the patient dose during a diagnostic coronary angiogram. ${ }^{48,49}$ Techniques have been developed to reduce the radiation dose with newer generation scanners, such as limiting x-ray emission during certain phases of image acquisition. 48

\section{Conclusion and Future Perspectives}

MSCT is a promising technique within the realms of noninvasive coronary imaging. With the advent of 64-slice MSCT, the diagnostic accuracy of CT coronary angiography has improved significantly and fares better in comparison to other currently available methods of noninvasive coronary imaging. With recent studies validating this, the role of MSCT in the evaluation of CAD is likely to grow in the future.

The major development resulting in improved diagnostic accuracy of MSCT has been the increase in the detector rows. In continuing this trend, 256-slice MSCT is being currently studied with the promise of increased accuracy and decreased scan time. ${ }^{50}$ In addition to developments in CT technology, studies looking at combining MSCT with other modalities of noninvasive cardiac imaging are being done. Protocols are being developed for combined evaluation of coronary anatomy and cardiac function with the development of hybrid 
scanners that combine MSCT with PET or SPECT, allowing simultaneous imaging of coronary tree, perfusion scan, cardiac metabolism and function. ${ }^{51}$ Co-registered MRI myocardial viability mapping and MSCT angiography are being studied for optimizing surgical revascularization planning. ${ }^{52}$ Furthermore, MSCT has been well studied for detection of pulmonary embolism and aortic dissection. The possibility of a wider use of MSCT in emergency room evaluations of chest pain is currently being considered as a test to achieve the so-called "triple rule out" in patients with chest pain, essentially excluding aortic dissection, pulmonary embolism and CAD. ${ }^{25,53}$

\section{Acknowledgments}

The authors would like to acknowledge Spencer Smith, MD of Radiology Associates, Tarrant Medical Imaging, Fort Worth, TX for reviewing this manuscript, providing MSCT figures and for technical advice.

\section{References}

1. Thom T, Haase N, Rosamond W, Howard VJ, Rumsfeld J, Manolio T, Zheng ZJ, Flegal K, O’Donnell C, Kittner S, Lloyd-Jones D, Goff DC Jr, Hong Y, Adams R, Friday G, Furie K, Gorelick P, Kissela B, Marler J, Meigs J, Roger V, Sidney S, Sorlie P, Steinberger J, Wasserthiel-Smoller S, Wilson M, Wolf P; American Heart Association Statistics Committee and Stroke Statistics Subcommittee. Heart disease and stroke statistics - 2006 update: a report from the American Heart Association Statistics Committee and Stroke Statistics Subcommittee. Circulation 2006;113:e85-e151.

2. Johnson LW, Lozner EC, Johnson S, Krone R, Pichard AD, Vetrovec GW, Noto TJ. Coronary arteriography 1984-1987: a report of the Registry of the Society for Cardiac Angiography and Interventions. I. Results and complications. Cathet Cardiovasc Diagn 1989; 17:5-10.

3. Johnson LW, Krone R. Cardiac catheterization 1991: a report of the Registry of the Society for Cardiac Angiography and Interventions (SCA\&I). Cathet Cardiovasc Diagn 1993;28:219-220.

4. Wexler L, Brundage B, Crouse J, Detrano R, Fuster V, Maddahi J, Rumberger J, Stanford W, White R, Taubert K. Coronary artery calcification: pathophysiology, epidemiology, imaging methods, and clinical implications. A statement for health professionals from the American Heart Association. Writing Group. Circulation 1996;94:1175-1192.

5. Shemesh J, Tenenbaum A, Fisman EZ, Apter S, Rath S, Rozenman J, Itzchak Y, Motro M. Absence of coronary calcification on double-helical CT scans: predictor of angiographically normal coronary arteries in elderly women? Radiology 1996;199:665-668.

6. Arad Y, Spadaro LA, Goodman K, Lledo-Perez A, Sherman S, Lerner G, Guerci AD. Predictive value of electron beam computed tomography of the coronary arteries. 19-month follow-up of 1173 asymptomatic subjects. Circulation 1996;93:1951-1953.

7. Shaw LJ, Raggi P, Schisterman E, Berman DS, Callister TQ. Prognostic value of cardiac risk factors and coronary artery calcium screening for all-cause mortality. Radiology 2003;228:826-833.

8. Achenbach S, Daniel WG. Noninvasive coronary angiographyan acceptable alternative? N Engl J Med 2001;345:19091910.
9. Agatston AS, Janowitz WR, Hildner FJ, Zusmer NR, Viamonte M Jr, Detrano R. Quantification of coronary artery calcium using ultrafast computed tomography. J Am Coll Cardiol 1990; $15: 827-832$

10. Callister TQ, Cooil B, Raya SP, Lippolis NJ, Russo DJ, Raggi P. Coronary artery disease: improved reproducibility of calcium scoring with an electron-beam CT volumetric method. Radiology 1998;208:807-814.

11. O'Rourke RA, Brundage BH, Froelicher VF, Greenland P, Grundy SM, Hachamovitch R, Pohost GM, Shaw LJ, Weintraub WS, Winters WL Jr, Forrester JS, Douglas PS, Faxon DP, Fisher JD, Gregoratos G, Hochman JS, Hutter AM Jr, Kaul S, Wolk MJ. American College of Cardiology/American Heart Association Expert Consensus document on electron-beam computed tomography for the diagnosis and prognosis of coronary artery disease. Circulation 2000;102:126-140.

12. O’Malley PG, Taylor AJ, Jackson JL, Doherty TM, Detrano RC. Prognostic value of coronary electron-beam computed tomography for coronary heart disease events in asymptomatic populations. Am J Cardiol 2000;85:945-948.

13. Burke AP, Kolodgie FD, Farb A, Weber DK, Malcom GT, Smialek J, Virmani R. Healed plaque ruptures and sudden coronary death: evidence that subclinical rupture has a role in plaque progression. Circulation 2001;103:934-940.

14. Achenbach S, Nomayo A, Couturier G, Ropers D, Pohle K, Schlundt C, Schmermund A, Matarazzo TJ, Hoffmann U, Daniel WG, Killip T. Relation between coronary calcium and 10 -year risk scores in primary prevention patients. Am J Cardiol 2003;92:1471-1475.

15. Haberl R, Becker A, Leber A, Knez A, Becker C, Lang C, Bruning R, Reiser M, Steinbeck G. Correlation of coronary calcification and angiographically documented stenoses in patients with suspected coronary artery disease: results of 1,764 patients. J Am Coll Cardiol 2001;37:451-457.

16. Hendel RC, Patel MR, Kramer CM, Poon M, Hendel RC, Carr JC, Gerstad NA, Gillam LD, Hodgson JM, Kim RJ, Kramer CM, Lesser JR, Martin ET, Messer JV, Redberg RF, Rubin GD, Rumsfeld JS, Taylor AJ, Weigold WG, Woodard PK, Brindis RG, Hendel RC, Douglas PS, Peterson ED, Wolk MJ, Allen JM, Patel MR; American College of Cardiology Foundation Quality Strategic Directions Committee Appropriateness Criteria Working Group; American College of Radiology; Society of Cardiovascular Computed Tomography; Society for Cardiovascular Magnetic Resonance; American Society of Nuclear Cardiology; North American Society for Cardiac Imaging; Society for Cardiovascular Angiography and Interventions; Society of Interventional Radiology.

ACCF/ACR/SCCT/SCMR/ASNC/NASCI/SCAI/SIR 2006 appropriateness criteria for cardiac computed tomography and cardiac magnetic resonance imaging: a report of the American College of Cardiology Foundation Quality Strategic Directions Committee Appropriateness Criteria Working Group, American College of Radiology, Society of Cardiovascular Computed Tomography, Society for Cardiovascular Magnetic Resonance, American Society of Nuclear Cardiology, North American Society for Cardiac Imaging, Society for Cardiovascular Angiography and Interventions, and Society of Interventional Radiology. J Am Coll Cardiol 2006;48:1475-1497.

17. Saia F, Schaar J, Regar E, Rodriguez G, De Feyter PJ, Mastik F, Marzocchi A, Marrozzini C, Ortolani P, Palmerini T, Branzi A, van der Steen AF, Serruys PW. Clinical imaging of the vulnerable plaque in the coronary arteries: new intracoronary diagnostic methods. J Cardiovasc Med (Hagerstown) 2006;7:21-28. 
18. Patel NA, Stamper DL, Brezinski ME. Review of the ability of optical coherence tomography to characterize plaque, including a comparison with intravascular ultrasound. Cardiovasc Intervent Radiol 2005;28:1-9.

19. Leber AW, Knez A, White CW, Becker A, von Ziegler F, Muehling O, Becker C, Reiser M, Steinbeck G, Boekstegers P. Composition of coronary atherosclerotic plaques in patients with acute myocardial infarction and stable angina pectoris determined by contrast-enhanced multislice computed tomography. Am J Cardiol 2003;91:714-718.

20. Hoffmann U, Moselewski F, Nieman K, Jang IK, Ferencik M, Rahman AM, Cury RC, Abbara S, Joneidi-Jafari H, Achenbach S, Brady TJ. Noninvasive assessment of plaque morphology and composition in culprit and stable lesions in acute coronary syndrome and stable lesions in stable angina by multidetector computed tomography. J Am Coll Cardiol 2006;47:1655-1662.

21. Nikolaou K, Sagmeister S, Knez A, Klotz E, Wintersperger BJ, Becker CR, Reiser MF. Multidetector-row computed tomography of the coronary arteries: predictive value and quantitative assessment of non-calcified vessel-wall changes. Eur Radiol 2003;13:2505-2512.

22. Leber AW, Knez A, Becker A, Becker C, von Ziegler F, Nikolaou K, Rist C, Reiser M, White C, Steinbeck G, Boekstegers P. Accuracy of multidetector spiral computed tomography in identifying and differentiating the composition of coronary atherosclerotic plaques: a comparative study with intracoronary ultrasound. J Am Coll Cardiol 2004;43:1241-1247.

23. Schroeder S, Kopp AF, Baumbach A, Meisner C, Kuettner A, Georg C, Ohnesorge B, Herdeg C, Claussen CD, Karsch KR. Noninvasive detection and evaluation of atherosclerotic coronary plaques with multislice computed tomography. J Am Coll Cardiol 2001;37:1430-1435.

24. Schroeder S, Kopp AF, Kuettner A, Burgstahler C, Herdeg C, Heuschmid M, Baumbach A, Claussen CD, Karsch KR, Seipel L. Influence of heart rate on vessel visibility in noninvasive coronary angiography using new multislice computed tomography: experience in 94 patients. Clin Imaging 2002;26:106-111.

25. Hoffmann U, Ferencik M, Cury RC, Pena AJ. Coronary CT angiography. J Nucl Med 2006;47:797-806.

26. Mollet NR, Cademartiri F, de Feyter PJ. Non-invasive multislice CT coronary imaging. Heart 2005;91:401-407.

27. Nieman K, Oudkerk M, Rensing BJ, van Ooijen P, Munne A, van Geuns RJ, de Feyter PJ. Coronary angiography with multi-slice computed tomography. Lancet 2001;357:599-603.

28. Leschka S, Alkadhi H, Plass A, Desbiolles L, Grunenfelder J, Marincek B, Wildermuth S. Accuracy of MSCT coronary angiography with 64-slice technology: first experience. Eur Heart J 2005;26:1482-1487.

29. Cademartiri F, Schuijf JD, Mollet NR, Malagutti P, Runza G, Bax JJ, de Feyter PJ. Multislice CT coronary angiography: how to do it and what is the current clinical performance? Eur J Nucl Med Mol Imaging 2005;32:1337-1347.

30. Sanz J, Rius T, Kuschnir P, Fuster V, Goldberg J, Ye XY, Wisdom P, Poon M. The importance of end-systole for optimal reconstruction protocol of coronary angiography with 16-slice multidetector computed tomography. Invest Radiol 2005;40:155-163.

31. Achenbach S, Moselewski F, Ropers D, Ferencik M, Hoffmann U, MacNeill B, Pohle K, Baum U, Anders K, Jang IK, Daniel WG, Brady TJ. Detection of calcified and noncalcified coronary atherosclerotic plaque by contrast-enhanced, submillimeter multidetector spiral computed tomography: a segment-based comparison with intravascular ultrasound. Circulation 2004;109:14-17.
32. Kopp AF, Schroeder S, Baumbach A, Kuettner A, Georg C, Ohnesorge B, Heuschmid M, Kuzo R, Claussen CD.

Non-invasive characterisation of coronary lesion morphology and composition by multislice CT: first results in comparison with intracoronary ultrasound. Eur Radiol 2001;11:16071611.

33. Ohnesorge BM, Hofmann LK, Flohr TG, Schoepf UJ. CT for imaging coronary artery disease: defining the paradigm for its application. Int J Cardiovasc Imaging 2005;21:85-104.

34. Achenbach S, Giesler T, Ropers D, Ulzheimer S, Derlien H, Schulte C, Wenkel E, Moshage W, Bautz W, Daniel WG, Kalender WA, Baum U. Detection of coronary artery stenoses by contrast-enhanced, retrospectively electrocardiographically-gated, multislice spiral computed tomography. Circulation 2001;103:2535-2538.

35. Knez A, Becker CR, Leber A, Ohnesorge B, Becker A, White C, Haberl R, Reiser MF, Steinbeck G. Usefulness of multislice spiral computed tomography angiography for determination of coronary artery stenoses. Am J Cardiol 2001;88:1191-1194.

36. Nieman K, Rensing BJ, van Geuns RJ, Munne A, Ligthart JM, Pattynama PM, Krestin GP, Serruys PW, de Feyter PJ. Usefulness of multislice computed tomography for detecting obstructive coronary artery disease. Am J Cardiol 2002;89:913-918.

37. Maintz D, Seifarth H, Raupach R, Flohr T, Rink M, Sommer T, Ozgun M, Heindel W, Fischbach R. 64-slice multidetector coronary CT angiography: in vitro evaluation of 68 different stents. Eur Radiol 2006;16:818-826.

38. Mahnken AH, Buecker A, Wildberger JE, Ruebben A, Stanzel S, Vogt F, Gunther RW, Blindt R. Coronary artery stents in multislice computed tomography: in vitro artifact evaluation. Invest Radiol 2004;39:27-33.

39. Budoff MJ, Achenbach S, Blumenthal RS, Carr JJ, Goldin JG, Greenland P, Guerci AD, Lima JA, Rader DJ, Rubin GD, Shaw LJ, Wiegers SE; American Heart Association Committee on Cardiovascular Imaging and Intervention; American Heart Association Council on Cardiovascular Radiology and Intervention; American Heart Association Committee on Cardiac Imaging, Council on Clinical Cardiology. Assessment of coronary artery disease by cardiac computed tomography: a scientific statement from the American Heart Association Committee on Cardiovascular Imaging and Intervention, Council on Cardiovascular Radiology and Intervention, and Committee on Cardiac Imaging, Council on Clinical Cardiology. Circulation 2006;114:1761-1791.

40. Dirksen MS, Bax JJ, de Roos A, Jukema JW, van der Geest RJ, Geleijns K, Boersma E, van der Wall EE, Lamb HJ. Usefulness of dynamic multislice computed tomography of left ventricular function in unstable angina pectoris and comparison with echocardiography. Am J Cardiol 2002;90:1157-1160.

41. Schuijf JD, Bax JJ, Salm LP, Jukema JW, Lamb HJ, van der Wall EE, de Roos A. Noninvasive coronary imaging and assessment of left ventricular function using 16-slice computed tomography. Am J Cardiol 2005;95:571-574.

42. Juergens KU, Grude M, Maintz D, Fallenberg EM, Wichter T, Heindel W, Fischbach R. Multi-detector row CT of left ventricular function with dedicated analysis software versus MR imaging: initial experience. Radiology 2004;230:403410.

43. Jongbloed MR, Dirksen MS, Bax JJ, Boersma E, Geleijns K, Lamb HJ, van der Wall EE, de Roos A, Schalij MJ. Atrial fibrillation: multi-detector row CT of pulmonary vein anatomy prior to radiofrequency catheter ablation - initial experience. Radiology 2005;234:702-709. 
44. Pache G, Saueressig U, Frydrychowicz A, Foell D, Ghanem N, Kotter E, Geibel-Zehender A, Bode C, Langer M, Bley T. Initial experience with 64-slice cardiac CT: non-invasive visualization of coronary artery bypass grafts. Eur Heart J 2006;27:976-980.

45. Stein PD, Beemath A, Skaf E, Kayali F, Janjua M, Alesh I, Olson RE. Usefulness of 4-, 8-, and 16-slice computed tomography for detection of graft occlusion or patency after coronary artery bypass grafting. Am J Cardiol 2005;96:16691673.

46. Kruger S, Mahnken AH, Sinha AM, Borghans A, Dedden K, Hoffmann R, Hanrath P. Multislice spiral computed tomography for the detection of coronary stent restenosis and patency. Int J Cardiol 2003;89:167-172.

47. de Feyter PJ, Nieman K. Noninvasive multi-slice computed tomography coronary angiography: an emerging clinical modality. J Am Coll Cardiol 2004;44:1238-1240.

48. Morin RL, Gerber TC, McCollough CH. Radiation dose in computed tomography of the heart. Circulation 2003; 107:917-922.

49. Hunold P, Vogt FM, Schmermund A, Debatin JF, Kerkhoff G, Budde T, Erbel R, Ewen K, Barkhausen J. Radiation exposure during cardiac CT: effective doses at multi-detector row CT and electron-beam CT. Radiology 2003;226:145-152.

50. Mori S, Kondo C, Suzuki N, Hattori A, Kusakabe M, Endo M. Volumetric coronary angiography using the 256-detector row computed tomography scanner: comparison in vivo and in vitro with porcine models. Acta Radiol 2006;47:186-191.

51. Namdar M, Hany TF, Koepfli P, Siegrist PT, Burger C, Wyss CA, Luscher TF, von Schulthess GK, Kaufmann PA. Integrated PET/CT for the assessment of coronary artery disease: a feasibility study. J Nucl Med 2005;46:930-935.

52. Setser RM, O'Donnell TP, Smedira NG, Sabik JF, Halliburton SS, Stillman AE, White RD. Coregistered MR imaging myocardial viability maps and multi-detector row CT coronary angiography displays for surgical revascularization planning: initial experience. Radiology 2005;237:465-473.

53. Savino G, Herzog C, Costello P, Schoepf UJ. 64 slice cardiovascular CT in the emergency department: concepts and first experiences. Radiol Med (Torino) 2006; 111:481-496

\section{Author Affiliations}

Gregory T. Wilson, DO

Department of Internal Medicine

Plaza Medical Center of Fort Worth*

Fort Worth, Texas

Prabhakaran Gopalakrishnan, MD

Department of Internal Medicine

JPS Health Network

Fort Worth, Texas

Tahir Tak, MD, Ph.D

Division of Cardiology

University of North Texas Health Science Center

Fort Worth, Texas

* Primary department and institution 